\title{
Hortênsia de Hollanda: a arte da educação em saúde para prevenção e controle das endemias no Brasil*
}

\author{
Hortênsia de Hollanda: the art of health education to prevent and \\ control epidemics in Brazil
}

\author{
Maria Cecília P. Diniz \\ Pesquisadora do Laboratório de \\ Educação em Saúde/Centro de \\ Pesquisas René Rachou/Fundação \\ Oswaldo Cruz. \\ Av. Augusto de Lima, 1715 \\ 30190-002 - Belo Horizonte - MG \\ - Brasil \\ cecilia@cpqrr.fiocruz.br

\section{Betânia Gonçalves Figueiredo \\ Professora do Departamento de História/Universidade Federal de Minas Gerais \\ Rua Bernardo Guimarães, 3101/402 \\ 30140-083 - Belo Horizonte - MG \\ - Brasil \\ beta@ufmg.br}

\section{Virgínia Torres Schall}

Pesquisadora titular do Laboratório de Educação em Saúde/Centro de Pesquisas René Rachou/Fundação Oswaldo Cruz.

Av. Augusto de Lima, 1715

30190-002 - Belo Horizonte - MG

- Brasil

vtschall@cpqrr.fiocruz.br
DINIZ, Maria Cecília P.; FIGUEIREDO, Betânia Gonçalves; SCHALL, Virgínia Torres. Hortênsia de Hollanda: a arte da educação em saúde para prevenção e controle das endemias no Brasil. História, Ciências, Saúde - Manguinhos, Rio de Janeiro, v.16, n.2, abr.jun. 2009, p.533-556.

Resumo

Apresenta a transcrição da aula da educadora brasileira Hortênsia Hurpia de Hollanda intitulada "Educação sanitária na profilaxia das endemias rurais", proferida em curso de atualização sobre endemias rurais e incluída nos Anais da Faculdade Fluminense de Medicina em dezembro de 1956. Evidencia o pioneirismo de Hollanda, cuja obra tem sido pouco explorada, considerando-se a dimensão de seu papel na área da educação em saúde no Brasil. A sensibilidade para os problemas sociais, a importância da participação da população e a atitude experimental são alguns dos aspectos presentes no texto da educadora, revelando ancoragem teórica avançada para a época e prática original e pioneira, que se mantém como ideal a ser alcançado nos dias atuais.

Palavras-chave: saúde pública; educação em saúde; ações comunitárias; história; Brasil.

\section{Abstract}

The article presents the transcription of a class given by Brazilian educator Hortênsia Hurpia de Hollanda entitled: "Educação sanitária na profilaxia das endemias rurais" [Sanitary education in the prophylaxis of rural epidemics], in a refresher course on rural epidemics and included in the Anais da Faculdade Fluminense de Medicina in December 1956. The annotated publication of the manuscript seeks to prove the pioneering efforts of Hollanda, whose work has been seldom investigated, considering the dimension of her role in the area of health education in Brazil. Sensitivity to social problems, the importance of the population's participation and an experimental attitude are some of the aspects presented in the educator's text, revealing an advanced theoretical grounding for her times and an original and pioneering practice that remains to this day as an ideal to be achieved.

Keywords: public health; health education; communitarian actions; Brazil. 
$\mathrm{O}$ texto "Educação sanitária na profilaxia das endemias rurais", encontra-se sob a guarda do Departamento de Arquivo e Documentação da Casa de Oswaldo Cruz (COC), da Fundação Oswaldo Cruz (Fiocruz). ${ }^{1}$ Trata-se de documento de nove folhas de papel ofício, datilografadas só na frente e numeradas no centro da borda superior. É texto único, narrativo, formado por quarenta parágrafos. Na capa, centralizado na borda superior, o título; no canto esquerdo, o timbre do Ministério da Saúde, Departamento de Endemias Rurais, Divisão de Cooperação e Divulgação; e o título centralizado na página. Mais abaixo, as seguintes observações: "Aula proferida pela Dra. Hortênsia de Hollanda, no Curso de Atualização de Conhecimentos sobre Endemias Rurais, na Faculdade Fluminense de Medicina, em dezembro de 1956 - In: Anais da Faculdade Fluminense de Medicina". Revelase, assim, que essa aula foi proferida principalmente para médicos e estudantes de medicina ou áreas afins, associando a educação em saúde ao controle das endemias brasileiras.

A expressão educação sanitária, no presente estudo de Hollanda, é empregada como sinônimo de educação em saúde. Sabe-se, entretanto, que analisando historicamente a educação em saúde no Brasil, o foco central da concepção de educação sanitária é a relação do homem com o meio ambiente, com a principal preocupação de promulgar regras e normas de prevenção de doenças através da orientação de um viver higiênico (Reis, 2006).

Pode-se dizer que o conceito atual da educação em saúde, predominante nas reflexões teóricas, expressa o processo teórico-prático que visa integrar os vários saberes - científico, popular e do senso comum -, possibilitando aos sujeitos envolvidos visão crítica e participação responsável e autônoma ante a saúde no cotidiano (Candeias, Rice, 1989; Candeias, Abujamra, Pereira, 1991; Candeias, 1997; Coelho, Almeida Filho, 2002; Reis, 2006).

A mudança de paradigma na educação em saúde é discutida por Briceño-León (1996) em debate com outros autores, em que se assinalam as questões relevantes do campo nas últimas décadas e se estabelecem postulados que podem orientar a educação em saúde. $\mathrm{O}$ autor parte das teorias da ação humana e propõe então sete teses sobre a educação sanitária, para a participação comunitária:

\footnotetext{
I- Não há um que sabe e outro que não sabe, mas dois que sabem coisas distintas;

II - A educação não ocorre só nos programas educacionais, mas em toda ação sanitária;

III - A ignorância não é um vazio a ser preenchido, mas um cheio a ser transformado;

IV - A educação deve ser dialogada e participativa;

V - A educação deve reforçar a confiança das pessoas em si mesmas;

VI- A educação deve procurar reforçar o modelo de conhecimento esforço/recompensa;

VII - A educação deve fomentar a responsabilidade individual e a cooperação coletiva.
}

Antes de nos determos na análise do texto de Hortênsia de Hollanda, apresentamos informações sobre sua trajetória e contextualizamos a época da referida aula, para destacar sua importância e centralidade na história da educação em saúde no Brasil. Tais informações, pouco conhecidas dos historiadores e pesquisadores da história da saúde pública e dos educadores em saúde pública, nos são úteis para interpretar as ideias e caracterizar o interesse da educadora por tão variada gama de assuntos. Visam também difundir e preservar sua memória, contribuindo para a popularização de sua biografia e de sua obra. Ademais, essas informações podem servir como contraponto para os estudos sobre a história da saúde pública do país no século XX. A força da obra de Hollanda está tanto em sua 
proposta de educação em saúde como em suas qualidades, sua maturidade e sabedoria, sua capacidade de ser e de viver apaixonada, evidente nos relatos das pessoas com quem compartilhou experiências (Alfabetizando..., 2001; Diniz, 2007).

\section{A trajetória da educadora Hortênsia de Hollanda: nota sobre vida e obra}

A entrevista intitulada "Alfabetizando o corpo: o pioneirismo de Hortênsia de Hollanda na educação em saúde" (Schall, 1999) apresenta a educadora, que nasceu em Corumbá, Mato Grosso do Sul, em 1917. Hollanda concluiu o curso de Língua e Literatura AngloGermânica na Faculdade de Filosofia do Rio de Janeiro em 1941 e o de Nutrição pelo Instituto de Nutrição da Universidade do Brasil, também no Rio de Janeiro, em 1949. Realizou sua especialização em Saúde Pública e Educação em Saúde na Universidade do Chile e na Universidade da Califórnia fez o mestrado em Public Health and Education. Em sua trajetória profissional, 45 anos de intenso trabalho (1942-1987), exerceu vários cargos e atividades docentes no Brasil.

Iniciou-se profissionalmente quando a sociedade brasileira vivia a etapa desenvolvimentista e de expansão diversificada da industrialização, sobretudo a partir da segunda metade da década de 1950, durante o governo de Juscelino Kubitschek, cuja política social se manifestou na intenção de promover o bem-estar geral do povo, com base na tese, então bastante difundida, de que o desenvolvimento econômico traz a solução dos problemas sociais e, em decorrência, melhora as condições de vida. Do ponto de vista político, o governo pretendia a preservação da ordem interna, a manutenção da paz social, a coesão com outros países, o desenvolvimento e a ajuda de capital estrangeiro, constituindo a modernização o núcleo dessa política desenvolvimentista.

Os discursos de educação em saúde da época enfatizavam a participação do indivíduo e da comunidade nas políticas públicas. A exigência de modernização visava tirar o homem rural do atraso cultural e integrá-lo ao processo de desenvolvimento. Para Lima e Zancan (1991), essa estratégia tinha como pressuposto básico a recomendação de que é preciso assumir responsabilidades para obter saúde.

Ornellas (1981) destaca que, a partir da década de 1950, a produção de textos sobre educação sanitária foi incentivada com a divulgação de documentos da Organização Mundial de Saúde (OMS), em que se discutiam principalmente os métodos e técnicas empregados na ação educativa e o papel dos profissionais (enfermeiras, educadores, professores e outros) no desempenho das tarefas a ela pertinentes.

A educação em saúde aparece na legislação que regula o funcionamento dos órgãos públicos de saúde e nas normas sanitárias, especificamente na lei 2.312, de 3 de setembro de 1954 - "Normas gerais sobre defesa e proteção da saúde" -, que estabelece, em seu artigo 3을 caber à União "manter órgãos de saúde e assistência que, entre outras atribuições, terá aquela de realizar a educação sanitária do povo". Diz ainda, no artigo 24, que "traçará as normas para a educação sanitária do povo, orientando o indivíduo na defesa de sua saúde. ... No currículo das escolas primárias do país serão incluídas noções de higiene e de saúde orientadas sob o ponto de vista sanitário pela autoridade sanitária competente". 
A respeito das endemias rurais, no governo de Juscelino Kubitschek foram tomadas decisões vinculadas às necessidades da produção. Vieira (1983) analisa o programa de saúde pública apresentado pelo governo Kubitschek em 1956, destacando como um dos aspectos a "ação decisiva na luta contra as endemias rurais e doenças de massa". No mesmo ano, uma reestruturação do Ministério da Saúde (desmembrado anteriormente, em 1953, do Ministério da Educação e Saúde) criou em seu âmbito o Departamento Nacional de Endemias Rurais (DNERu), com a competência de organizar e executar pesquisas e promover o combate a malária, leishmaniose, doença de Chagas, esquistossomose, febre amarela, peste, brucelose, ancilostomose, filariose, hidatidose, bouba, bócio endêmico, tracoma e outras endemias (Lima, Pinto, 2003). A criação do DNERu daria suporte às metas de desenvolvimento e produtividade, ao atuar em áreas que constituam "pontos críticos das vias principais de transporte e possuam fatores evidentes de desenvolvimento econômico, entravadas pela falta de condições sanitárias do meio", segundo Oshiro (1988, p.77). A revisão dessa autora sobre o processo revela que o combate às endemias rurais passou a ser centralizado e que $o$ setor de saúde pública ganhou significação relativa, uma vez que, para o governo Kubitschek, a melhoria das condições de saúde e de vida estava na dependência do desenvolvimento econômico. Pretendia-se, com as campanhas de combate às endemias rurais, recuperar áreas com possibilidade de ocorrer a acumulação capitalista.

As campanhas, em que pesem suas especificidades, eram organizadas tendo por base assistência médica, controle do ambiente pelo saneamento, pesquisas e educação sanitária. Esta última tinha por função mediar as campanhas de combate às endemias rurais. As práticas sanitárias do DNERu eram embasadas em medidas de promoção, proteção e recuperação da saúde, considerando-se que o processo saúde/doença envolve a interação de homem, agente etiológico (micro-organismo) e meio ambiente.

A educação em saúde no DNERu assumiu posição de destaque entre as práticas sanitárias e visava contribuir para a reorganização da visão de mundo das camadas populares. Orientava-se pela concepção de multicausalidade do processo saúde/doença, com ênfase nos aspectos ecológicos. Coerente com tal concepção, que explica mecanicamente o processo saúde/doença, concebia a educação como plano situado fora das determinações econômicas e políticas, assumindo a prática pedagógica uma postura de falsa neutralidade. Buscava-se superar a prática pedagógica tradicional em saúde com a introdução de inovações metodológicas fundamentadas na psicologia cognitivista, que enfatiza os processos mentais envolvidos na aprendizagem, isto é, o domínio de habilidades mentais para a assimilação dos conteúdos (Oshiro, 1988).

Nessa ocasião Hollanda ingressou no DNERu com a incumbência, um tanto genérica, de observar e oferecer propostas de educação em saúde para contribuir com o controle da esquistossomose, uma das endemias cujo combate estivera antes a cargo do Serviço Nacional de Malária - SNM (1953-1954). O SNM obtivera sucesso na luta contra a malária, e o então diretor Mário Pinotti conquistara grande prestígio (Hollanda, 1996). A queda dos altos índices da malária foi atribuída ao modelo então adotado, e admitia-se adotar igual procedimento na luta contra a esquistossomose.

Refletindo sobre sua trajetória profissional, Hollanda descreve e faz críticas às diretrizes do serviço. Observou que, naquele momento, estavam na gerência das campanhas os 
médicos, profissionais ainda pouco receptivos a enfoques voltados para a educação. Os agentes de saúde e guardas sanitários, incumbidos da efetivação das campanhas junto às populações, limitavam-se à utilização de medicamentos apropriados. Articulavam-se com postos de saúde em ações circunscritas, orientando sobre os cuidados imediatos indispensáveis e seus benefícios. Ao encontrar essa situação, Hollanda apresentou propostas para o DNERu e sugeriu uma modificação radical nos procedimentos vigentes. Um dos principais aspectos dessa mudança envolvia a participação diferenciada da população-alvo da campanha e, para tanto, a formação de agentes de saúde: "No nível de execução de ações locais, atingindo o processo de formação de agentes, abrindo espaço para a participação das populações envolvidas, considerando o meio ambiente; no nível de direção para a integração de educadores no corpo técnico do departamento" (Hollanda, 1996, p.8). Assim, pode-se dizer que, no DNERu, Hortênsia de Hollanda iniciou a mais expressiva contribuição profissional na área de educação em saúde, com seu esforço de modificação dos enfoques então adotados.

A reincidência das endemias vinha revelando a pouca eficácia das campanhas, não obstante seus sucessos promissores de curto prazo. Entretanto, resultados imediatos são sempre sedutores, e vencer resistências à mudança de enfoque em programas de forte repercussão nacional, que mobilizavam a imprensa, o país e tinham apelo político, não foi tarefa fácil. Para enfrentá-la, Hollanda realizou lento e persistente trabalho: organizou equipes multiprofissionais e abriu caminho para a reformulação ambicionada. Uma das preocupações da educadora era descobrir como 'quebrar' a mentalidade rígida e disciplinada dos agentes de saúde, que os conduzia a uma visão fragmentada da realidade, produto de uma formação típica da época. Suas atenções voltaram-se também para a direção do DNERu, que acompanhava, às vezes com ceticismo, os trabalhos desenvolvidos. Em seu relato, Hollanda (1996, p.9) afirma: "Difícil substituir a expectativa de resultados rápidos, via aplicação de medicamentos, por processos de mudança comportamental, mais lentos, embora duradouros".

A educadora concentrou grande parte dos objetivos de seu trabalho no treinamento de equipes para o DNERu, que, em sua concepção, deviam contemplar instrumentos intelectuais que estimulassem a capacidade de descobrir, pensar e inventar. Era importante promover oportunidades de escolha e decisão diante de situações problemáticas de saúde. Para Hollanda, os cursos não eram espaços de reunião de professores e alunos ou agentes em torno de um currículo; eles deviam favorecer uma situação de 'desaprendizado inicial', de descobertas de novas realidades, de modo que fosse possível reconhecer os problemas de saúde sob uma nova perspectiva e 'enxergar' melhor as populações, seus problemas e dilemas de sobrevivência e os modos de lidar com eles.

A proposta era trabalhar com as populações com o propósito de compreender suas percepções quanto à realidade e às questões relativas à saúde. Nesse cenário, os agentes procurariam inserir conhecimentos específicos sobre a prevenção/cura/melhoria das condições de saúde, realizando os mapeamentos locais necessários à sua intervenção. As técnicas de abordagem local resultariam desse processo de formação e seriam permanentes, durante toda a condução dos projetos contra as endemias e os esforços de envolvimento das populações para o alcance dos objetivos identificados. A dinâmica do relacionamento 
agente/pessoas e populações/projeto institucional seria realizada mediante a participação de cada um desses componentes, cabendo ao agente o papel principal de 'criador de situações', que conduziriam, no nível local, à desejada melhoria dos padrões de saúde. Os processos de formação nos cursos se completariam com experiências de campo. Enfim, Hollanda defendia que o educador em saúde não atuava apenas com base nos objetivos institucionais, pois a estes deveriam somar-se os interesses das populações.

Pode-se dizer que a proposta de Hollanda representou uma ruptura com as propostas e concepções vigentes de educação sanitária. As intervenções de saúde, planejadas nos gabinetes e executadas independentemente das características socioculturais das populações, foram substituídas por outras que contavam com a participação das populações envolvidas, e nesse novo percurso aprendiam tantos os agentes de saúde como as comunidades.

Hollanda dedicou-se a várias atividades no DNERu, sendo incentivadora da formação de equipes multiprofissionais (epidemiologia, psicossocial e saúde) para assessoramento de trabalho de pesquisa, planejamento e reciclagem, com o objetivo de inovar e reformular concepções e ações de controle das endemias rurais no Brasil. Em suas primeiras visitas às áreas endêmicas de esquistossomose no Nordeste (1955-1957), conheceu os estudos desenvolvidos pela equipe de Samuel Barnsley Pessoa, em dois distritos rurais de João Pessoa ( $\mathrm{PB})$, a partir de postos locais de atendimento e tratamento de esquistossomose. Atendendo à sugestão desse professor, iniciou um levantamento das condições de vida e saúde e das percepções que os habitantes tinham de sua própria situação. Seguiu-se a ele um processo de envolvimento da comunidade na discussão de projetos de melhoria das condições ambientais, em face da existência da esquistossomose, que transformou os dois distritos em campos experimentais para capacitação e desenvolvimento de pessoal destinado à ação educativa em saúde.

A importância da divulgação do texto de Hollanda, enquanto ainda estava atuando no DNERu, deve-se ao fato de que a educadora expõe ali seu pioneirismo, ao propor a substituição da educação sanitária tradicional - assinalada pelo higienismo, entendido como prática médica só voltada para a disseminação de noções de higiene e saneamento, por meio de conceitos ultrapassados em relação aos programas propostos - por uma nova abordagem, que integrava o homem ao contexto social em que vive, de forma crítica e participativa.

As ideias de envolvimento e participação das populações nos programas de saúde, como proposto por Hortênsia de Hollanda, encontraram resistência de diversas áreas, sobretudo a biomédica, que defendia prioridade para a produção de vacinas e medicamentos e o controle químico de vetores. Tal situação persiste, e até hoje essa área congrega maior número de pesquisadores e maior volume de recursos (Schall, Massara, Diniz, 2008).

Os defensores das medidas de controle verticais - que promovem a redução da transmissão das principais endemias com a medicação da população, ou seja, com ênfase curativa - imbuídos também de uma tradição autoritária e normatizadora ${ }^{2}$, questionaram até mesmo o que era considerado positivo na proposta de Hollanda: a independência da população e sua autonomia para gerir os próprios problemas. Na visão de alguns responsáveis, a participação local das comunidades significava, sob o aspecto político, perda de poder. Já para a educadora, a participação das populações, seu engajamento consciente no planejamento e na realização dos projetos locais, contribuiria positivamente 
para o sucesso destes, pois a base da atuação participativa é a provocação de estímulos que despertam interesse, indagação e avaliação comparativa de situações.

Considerada ousada para a época, Hortênsia de Hollanda promoveu verdadeira revolução nos trabalhos de saúde com populações. Segundo Schall (1999, p.149), ela "abriu espaço para a participação da comunidade, num enfoque ambientalista e integrador, avançado e pioneiro em seu tempo, e, até hoje, por poucos alcançado".

Vale destacar que Hollanda ainda atuou como health education officer pela South Pacific Commission, em países e territórios da Melanésia, Polinésia e Micronésia, e como consultora da OMS no México, Costa Rica, Honduras, Guatemala, Paraguai e Argentina, além de coordenar projetos de pesquisa, desenvolvimento e avaliação de materiais educativos em saúde no Brasil. Sem dúvida, essas experiências internacionais contribuíram com aprendizagens no que concerne ao condicionamento cultural, e aguçaram sua sensibilidade para uma gama de fatores subjetivos, vinculados à cultura, envolvidos nos processos de atuação em saúde pública.

Em paralelo a sua ampla atuação na prática da educação em saúde, Hortênsia de Hollanda participou como professora de vários cursos para a área de saúde pública e realizou pesquisas, algumas com financiamento do Conselho Nacional de Desenvolvimento Científico e Tecnológico (CNPq). Em reconhecimento a seu trabalho, foi homenageada na $2^{\text {a }}$ Conferencia Latino-Americana de Promoción y Educación para la Salud, em Santiago, Chile (1996), e recebeu, em 1999, o título de Doutora Honoris Causa da Escola Nacional de Saúde Pública, da Fundação Oswaldo Cruz.

De toda essa experiência emergem o relato dos que trabalharam com Hollanda (Alfabetizando..., 2001; Diniz, 2007), alguns documentos escritos e outros, poucos, publicados, além dos materiais educativos desenvolvidos sob sua coordenação ou parceria. Entre eles encontra-se o livro Saúde como compreensão de vida (Hollanda, 1977), resultado da coordenação do projeto Elaboração e Experimentação de Novos Materiais Para o Ensino de Saúde, em convênio do Ministério da Saúde e da Divisão Nacional de Educação Sanitária com o Ministério da Educação e Cultura e o Programa de Melhoria e Expansão do Ensino. Elaborado com outros pesquisadores/educadores e um grande número de professores do então primeiro grau (hoje ensino fundamental) dos estados de Minas Gerais, Rio Grande do Sul, Bahia e Rio de Janeiro, o livro focaliza a definição das necessidades de informação em saúde, os métodos para seu ensino e a experimentação dos textos preliminares.

Precursora da educação em saúde no Brasil, pode-se dizer que Hollanda trouxe para o debate ideias de várias áreas, como antropologia, sociologia, pedagogia, psicologia e outras que se mostram cruciais para proporcionar perspectiva mais abrangente dos fenômenos observados em saúde. Suas reflexões estão fundadas na defesa da capacidade criativa humana, como descreve: "Creio poder confirmar minha crença pessoal na capacidade criadora do ser humano para superar suas próprias dificuldades. Apesar dos problemas de fome, miséria, atraso, esquecimento, ainda consegue mobilizar forças para lutar por sua sobrevivência" (Hollanda, 1996, p.15).

Essa sensibilidade humanista está claramente evidenciada na aula aqui apresentada, que discutiremos a seguir, destacando trechos que nos parecem relevantes para a compreensão mais abrangente das ideias da educadora quanto à questão da educação em 
saúde associada ao controle das endemias brasileiras. Para tal, dialogaremos com autores que podem ou não ter sido de conhecimento da educadora, mas que apresentam ideias comuns a ela. Apontaremos reflexões que demonstram a ousadia de Hollanda para a época, a criatividade de suas perspectivas e as inovações propostas para a área de educação e saúde pública, muitas delas debatidas, aplicadas e valorizadas nos dias atuais.

\section{"Educação sanitária na profilaxia das endemias rurais no Brasil": a integração do homem ao contexto social}

Acreditando que o conhecimento conduz à mudança de comportamento, Hortênsia de Hollanda inicia a referida aula enfatizando o papel da educação sanitária na profilaxia e no controle de endemias. Estudos recentes (Rosenbaum et al., 1995; Chiavaralloti Neto, Moraes, Fernandes, 1998; Diniz, Braga, Schall, 2003; Lefèvre et al., 2004; Gazzinelli, Reis, Marques, 2006) demonstram o que Hollanda destaca: não existe concordância entre conhecimento e adoção de medidas preventivas por parte da população. Esses estudos revelam que a pouca efetividade das estratégias propostas nas campanhas de controle às doenças decorre de outros equívocos, que Hollanda também mostra no decorrer de seu texto. Ela aponta a pouca atenção dos educadores e formuladores de programas e projetos aos conceitos prévios e às possíveis crenças que a população tem a respeito das questões de saúde. Ressalte-se também a falta de incentivo dos programas de saúde da época com relação à participação na elaboração das propostas educativas e na discussão de suas prioridades. Segundo Hollanda, o que se promovia então não passava de informações científicas sobre determinados assuntos de saúde. Utilizando o caso da esquistossomose e o conhecimento dos modos de transmissão da doença, relata que "apenas uma reduzida porcentagem da população modifica efetivamente suas atitudes e práticas" e ainda que "as pessoas que respondem ao apelo do material educativo distribuído são, significativamente, aquelas que já demonstram interesse por questões de saúde e que pertencem a grupos econômicos mais favorecidos".

A partir desses pressupostos, Hollanda desenvolve uma concepção diferenciada de intervenção na área da saúde. A adesão aos programas só ocorre se a população se vê inserida no processo de solução de um problema. Essa equação, por sua vez, só se processa à medida que a população é integrada ao processo de conhecimento relativo ao problema em questão. Ou seja, é necessário conhecer a população, compreender sua forma de lidar com a situação relativa à saúde, entender seus hábitos e costumes. Em seguida é preciso desenvolver um processo de compreensão da importância das mudanças culturais e ambientais, visando preservar determinado nível de saúde ou alterá-lo. Só compactuam e participam das mudanças as comunidades que se sentem efetivamente sensibilizadas. Deve haver, portanto, adesão decorrente de reflexão, entendimento, aceitação e incorporação; jamais uma imposição via decretos ou ordens do mundo da ciência e do poder político.

Hollanda apresenta suas ideias com base em estruturas complexas, mas o faz de forma simples e de fácil compreensão por seus pares de ação direta e não pelos acadêmicos, o que talvez explique, por um lado, pouco ter publicado na área acadêmica e, por outro, o verdadeiro fascínio por suas energia e ideias em todos os relatos dos que com ela conviveram. 
Para Hollanda, deve-se à concepção racionalista de homem - "capaz de raciocinar das premissas às conclusões", usando a lógica - a ideia de que através do conhecimento é possível modificar condutas. Lembra que "o homem é antes de tudo um animal afetivo, cujo pensamento e ação sofrem irremediavelmente as influências do meio em que vive e do jogo das interações entre o seu organismo total e o ambiente em que ele se desenvolve". Valorizando o afeto, a educadora partilha as abordagens apresentadas nas obras de Piaget (1981, 2001), Vygotsky (1996) e Wallon (1986), sobre o funcionamento psíquico humano integrando cognição e afetividade, razão e emoções.

A ideia de que afetividade e cognição são inseparáveis, indissociáveis em todas as ações simbólicas e sensório-motoras levou Piaget a postular que toda ação e todo pensamento comportam um aspecto cognitivo, representado pelas estruturas mentais, e um aspecto afetivo, representado por uma energética, que é a afetividade. Para ele, na relação do sujeito com os objetos, com as pessoas e consigo mesmo existe uma energia que direciona seu interesse para uma situação ou outra e à qual corresponde uma ação cognitiva que organiza o funcionamento mental: "É o interesse e, assim, a afetividade que fazem com que uma criança decida seriar objetos e quais seriar" (Piaget, 1981, p.10; tradução livre). Posteriormente o autor incorporou outro tema na relação entre afetividade e cognição, o dos valores, mostrando que eles se originam das trocas entre o sujeito e o mundo externo a partir de suas relações com os objetos, com as pessoas e consigo mesmo (Piaget, 2001).

Encontram-se nos textos e práticas de Hollanda aspectos enfatizados na obra de Vygotsky e Wallon, autores que têm muitos pontos em comum ao abordar a afetividade. Ambos assumem o caráter social do desenvolvimento humano e demonstram que as manifestações emocionais, de caráter orgânico, vão ganhando complexidade e passam a atuar no universo simbólico. Dessa maneira, ampliam-se as formas de manifestações, constituindo os fenômenos afetivos. Da mesma forma, defendem a íntima relação entre o ambiente cultural/ social e os processos afetivos e cognitivos, aspectos, afirmam eles, que interagem e se influenciam mutuamente.

Hortênsia de Hollanda expressa a necessária revisão do conceito de conhecimento por todos que assumem a tarefa de educar e defende a ideia de que nenhum médico - fazendo referência aos que trabalham na área da saúde - se deve "evadir de sua função pedagógica".

Considerando as dimensões da afetividade e de suas formas e presença no contexto formativo do profissional da saúde, faz-se importante apresentar algumas considerações que talvez integrem as preocupações de Hollanda.

As relações entre afetividade e processo ensino/aprendizagem podem ser analisadas quando se focaliza o cotidiano das escolas médicas, especialmente os protagonistas envolvidos nessa relação: o professor, o aluno e o cliente/paciente. "Em tempos idos, praticamente sem equipamentos diagnósticos e terapêuticos, o sucesso do médico dependia principalmente de uma boa relação médico-paciente" (Gomes, 2002, p.21). A formação dos profissionais de saúde precisa desenvolver mais do que cumpridores de tarefas; deve proporcionar-lhes oportunidades de análise que contemple as determinações do contexto histórico e os valores culturais e políticos, de modo a favorecer uma reflexão crítica que considere aspectos sociais, políticos, morais e éticos (Silva, 1997). 
$\mathrm{O}$ atendimento médico inclui pacientes que, marcados por determinada cultura e limitações materiais, não se submetem passivamente aos tratamentos prescritos. Assim, medicar é também um ato educativo e de negociação com os saberes e práticas populares de saúde. Os médicos têm enfrentado essa questão pelo que chamam de 'bom senso médico', aprendido pela imitação dos mestres e por sua própria experiência. Vasconcelos (2004) mostra que, ao conviver com a dinâmica do processo de adoecimento e de cura no meio popular, interagir com movimentos sociais locais e entrar em contato com pesquisadores, profissionais de saúde e professores, muitos desses profissionais reorientam suas práticas de modo a enfrentar de forma mais global os problemas de saúde que encontram. Em alguns dos serviços em que pessoas-chave e profissionais de saúde identificados com os interesses dessa população conseguem conquistar maior controle de seu funcionamento, surgem algumas experiências pioneiras que avançam bastante na superação das práticas tradicionais do campo médico. Talvez fosse este o sonho de Hortênsia de Hollanda: ver o exemplo do pai médico, "sua capacidade para ouvir as queixas dos doentes, vontade de compreender as situações geradoras de doenças, penetrar na raiz dos fatores antes de intervir" (Hollanda, 1996, p.20), alcançar o cuidado à saúde na sociedade atual e resultar na maior interrelação de diversas profissões, especialidades, serviços, doentes, familiares, vizinhos e organizações sociais locais envolvidos num problema específico de saúde, fortalecendo e reorientando suas práticas, saberes e lutas não mais a partir de uma norma considerada científica e universalmente correta, mas a partir de seus interesses, valores e entendimentos.

A educadora afirma que "o problema da educação sanitária não é propriamente de dar conhecimentos, especialmente quando se trata daqueles grupos culturalmente mais atrasados, mas sim de reestruturação de atitudes, de concepções de vida já existentes". Para ela a concepção de vida das pessoas é que as ajuda a interpretar o mundo em que estão inseridas; por isso afirma ser necessária a compreensão do todo de que fazem parte e de suas atitudes perante as doenças, sendo a tarefa da educação em saúde modificar "essa concepção mais alta da qual decorrem todas as outras, mais específicas".

Sua formação filosófica vem à tona quando critica a fragmentação do homem decorrente da análise dos especialistas: "Em saúde pública, a educação sanitária representa um esforço no sentido de integração, de encarar o homem, objeto da medicina, dentro do contexto social em que se criou e em que vive esse homem". Em sua opinião, para que essa abordagem seja compreendida é preciso considerar a cultura, reguladora de todas as necessidades individuais dos homens, como demonstram as inúmeras soluções para problemas básicos como alimentação ou reprodução.

Para o planejamento de programas com ações educativas em saúde, Hollanda aponta outro conceito importante, o de mudança cultural: "Com o avanço da tecnologia e o fantástico aperfeiçoamento dos meios de comunicação, a nossa geração pode assistir e medir, especialmente nos centros urbanos, as modificações que se operaram na estruturação dos valores, nos papéis atribuídos aos diferentes membros ou grupos da sociedade, produzidas pela rapidez com que as ideias circulam". Esse trecho demonstra como a educadora percebe o impacto dos meios de comunicação junto à população, e não apenas nos centros urbanos - destaque-se que na época em que a aula foi escrita não se contava com celulares e internet. Para ela, é preciso que a educação em saúde promova contatos 
pessoais, aproximando grupos primários e elaborando programas coordenados por entidades da comunidade, tais como a escola e a igreja.

Nota-se que Hollanda defende a saúde pública como possuidora de grande força de mudança cultural, "desde que ela aborde os problemas em sua totalidade, procurando a participação da população, fazendo com que cada atividade de assistência médica ou de profilaxia vise ao levantamento das possibilidades físicas e espirituais de cada indivíduo e da comunidade em geral". A educação em saúde, acredita a educadora, precisa ser encarada como programa de ação em que ocorra o envolvimento de todos.

Ao propor essa, até então, nova abordagem de educação em saúde, Hortênsia de Hollanda se antecipou às discussões de antropólogos relativas a uma visão alternativa à da biomedicina para o conceito de doença (Fabrega, 1974; Good, 1977, 1994; Kleinman, 1980; Young, 1976, 1982): a da antropologia médica, que tenta compreender a influência da cultura na maneira como os indivíduos percebem a doença e estabelecem relações com os diversos sistemas de saúde. Reunindo, no campo da etnomedicina, reflexões da antropologia simbólica, da semiótica, da psicologia e considerações sobre a eficácia da cura, esses estudiosos se dedicam à construção de paradigmas em que o biológico esteja articulado com o cultural (Bibeau, 1981). A doença, acreditam eles, não é evento primariamente biológico, mas é concebida em primeiro lugar como um processo experienciado, cujo significado é elaborado conforme episódios culturais e sociais, para só depois se tornar evento biológico. Não se trata portanto de um estado estático, mas de um processo que requer interpretação e ação no meio sociocultural, o que implica negociação de significados na busca da cura (Staiano, 1981).

Antecipando-se à Conferência Internacional Sobre Cuidados Primários de Saúde, realizada em 1978 em Alma-Ata (Brasil, 2001) e a vários movimentos posteriores (Conferência do Canadá, que resultou na Carta de Ottawa em 1986; Conferência da Austrália, com a Declaração de Adelaide, em 1988; Conferência Mundial Sobre o Meio Ambiente, realizada no Rio de Janeiro em 1992, entre outros), Hollanda mostra que os educadores em saúde são peças-chave na geração de uma nova cultura da saúde, caracterizada pela humanização e integralização do cuidado ao ser humano, caminho para o desenvolvimento preconizado pela Declaração de Alma-Ata.

Hollanda destaca a importância do educador em saúde quando mostra que sua identificação emocional com a tarefa é fundamental para "assegurar a participação individual e coletiva das populações nos programas". Defende que sem identificação emocional não é possível obter resultados duradouros ou de profundidade e afirma: "Qualquer serviço de saúde, para ser educativo, para ter continuidade no tempo e no espaço, terá que contar com pessoal capaz de sentir e de compreender os aspectos psicológicos, sociais e econômicos do problema médico".

Em seu entendimento, cada médico deve ter formação de educador, a fim de que ocorram efetivas trocas de ideias e sentimentos. Assim, "o médico deveria ser preparado para perceber e compreender as forças sociais como fatores epidemiológicos e determinantes de certos quadros da doença". Para a educadora, é essencial desenvolver a capacidade de compreender e se fazer compreendido. Suas reflexões vão ao encontro do que hoje postulam os educadores populares em saúde: 
Uma atitude reflexiva e crítica diante da sociedade, a compaixão com o sofrimento humano, a sensibilidade com a sutileza das manifestações das dinâmicas subjetivas e o engajamento com os movimentos sociais não podem ser ensinados massivamente através de disciplinas teóricas. Mas se pode criar situações pedagógicas, orientadas pela experiência acumulada da Educação Popular, em que são problematizadas as vivências e indignações dos profissionais em sua relação com a realidade, compartilhadas iniciativas de enfrentamento e busca de soluções e valorizada a curiosidade na busca de entendimento das raízes das questões sociais mais importantes (Vasconcelos, 2004, p.81).

Ao falar sobre a exigência de "certa dose de espírito missionário" no trabalho com saúde pública, Hortênsia de Hollanda parece mostrar que as políticas sociais implementadas pelo Estado brasileiro nunca foram capazes de atender às demandas da população, deixando excluído grande contingente de sujeitos ou restringindo-lhe o acesso. Pode-se interpretar tal opinião sob várias perspectivas. Primeiramente, pelo fato de as políticas públicas tradicionais não considerarem o componente cultural das populações envolvidas. Em segundo lugar, como decorrência da imposição de um saber considerado científico e oficial que, para se impor, costuma desprezar o conhecimento popular.

Disso resulta que as pessoas pertencentes às classes populares se veem obrigadas a buscar estratégias capazes de minimizar ou suprir suas necessidades. Assim, a educadora antecipa o debate em torno da Teoria do Apoio Social, originada em meio a autores norte-americanos, para quem o apoio social é qualquer informação (falada ou não) ou auxílio material oferecido por grupos ou pessoas que se conhecem, do qual resultam efeitos emocionais e comportamentos positivos. Trata-se de processo recíproco, isto é, que gera efeitos positivos tanto para o receptor como para quem oferece o apoio, o que permite a ambos uma maior sensação de controle sobre suas vidas, além da percepção de que as pessoas necessitam umas das outras (Minkler, 1985, conforme Valla, 1999).

Incitada a esclarecer a importância das motivações, Hollanda recorre ao exemplo vivido em um município de Pernambuco, para concluir que os êxitos nos trabalhos educativos em saúde só serão alcançados com a ação. Com essa afirmação a educadora parece dialogar com as ideias de Paulo Freire. Ao afirmar que "o pensamento se modifica através da ação. O pensamento da gente simples não se modifica na contemplação das coisas. A mão é um instrumento maravilhoso para a transformação do pensamento", Hollanda compartilha com seu contemporâneo a ideia de que o problema central da educação não é a mera alfabetização, mas colaborar para que o homem assuma sua dignidade enquanto tal, como detentor de cultura própria e capaz de fazer história. Segundo Paulo Freire (1994), o homem que acredita em si é capaz de dominar os instrumentos de ação a sua disposição.

Contemporâneo de Hollanda, Paulo Freire acreditava que as questões e os problemas principais da educação não são pedagógicos, mas sim políticos. Sua proposta, a pedagogia crítica como práxis cultural, contribuiu para revelar a ideologia encoberta na consciência das pessoas. Seu trabalho transpira dedicação e coerência, aliadas à convicção de luta por uma sociedade justa, voltada para o processo permanente de humanização, sem que ninguém seja excluído ou posto à margem da vida. Paulo Freire provou que é possível educar para responder aos desafios da sociedade e que a educação é instrumento de transformação global do homem e da sociedade, tendo como essência a dialogicidade (Freire, 1975, 1976, 1994). 
Tal como Freire, Hollanda acreditava ser necessária a participação das pessoas da comunidade nas atividades de profilaxia, desde o planejamento até a execução. $\mathrm{O}$ trabalho em grupos para discussão dos problemas locais as ajudaria a compreender melhor seus problemas, seus dilemas e os modos de lidar com eles. Segundo o novo pressuposto da ação em saúde pública, todos os agentes envolvidos deveriam estar preparados para lidar com a diversidade cultural, em uma relação de complemento e diálogo.

As preocupações da educadora não se limitam ao elemento humano: ela se reporta às formas associativas existentes, aos recursos institucionais, às condições físicas locais de sobrevivência, bem como aos vários indicadores da organização de vida local - tipos de habitação, recursos hídricos, clima, topografia, meios de comunicação, escolas, postos de saúde, atendimento hospitalar, comércio e transporte, crenças, hábitos e opiniões, e modos de expressá-los.

Hollanda narra fatos na intenção de demonstrar que é possível desenvolver o senso de comunidade e coletividade e criar situações que promovam a competição construtiva, o trabalho e engajamento comunitário em torno de um projeto de controle da esquistossomose. A emoção com que expõe os acontecimentos funciona como um filtro para o leitor, e por seu intermédio revela-se cada aspecto da ação em saúde pública que propõe. No entanto, afirma, "não existem métodos padronizados para essa tarefa de educação sanitária, pois a educação é fundamentalmente educação social".

Por não haver métodos padronizados e pela necessidade de adoção de atitudes experimentais, Hollanda mostra a importância da intuição, emoção e sensibilidade no trabalho em saúde. Sobre o tema, Vasconcelos (2006) aponta que se torna cada vez mais evidente, nos trabalhos de saúde, a superioridade da presença, do olhar e do afeto sobre a dimensão racional e lógica da palavra: "A palavra parece repercutir muito mais quando expressa sentimentos e valores do que como elemento de transmissão de conhecimentos ... hoje, a carência de informações técnicas tornou-se relativamente menos importante, tornando mais significativas as práticas educativas que lidam com as motivações e os sentimentos envolvidos nos problemas de saúde" (p.113)

A literatura antropológica e sociológica denomina informante-chave aquela pessoa que pertence a um grupo a ser estudado ou que conhece bem o assunto pesquisado, sendo assim fonte preciosa de informações (WHO, 1994). A proposta de Hollanda é localizar, na comunidade, pessoas capazes de colaborar com as atividades educativas, tanto na investigação inicial quanto no desenvolvimento do trabalho - pessoas-chave, poderíamos designar hoje -, de modo a gerar parcerias duradouras e práticas inovadoras que muito ampliam o papel de cada um, sobretudo na sustentabilidade do processo educativo.

Ao falar sobre reestruturação de atitudes e modificação de comportamentos por meio de novas situações, conhecimentos e interações, Hortênsia de Hollanda insere outro tema que viria a ser alvo de reflexões e debates: a educação de adultos. Em severa crítica à educação e à formação do professorado da época, questiona o pouco interesse e esforço para com os adultos, defendendo que "não há justificativa para a difundida ideia de que os adultos não aprendem" e que "é possível uma apreciável reestruturação das atitudes em relação a todos os setores da vida derivada do trabalho educativo de adultos no campo da saúde. Verdadeiros líderes comunais surgem dos grupos trabalhados". Ilustra com um 
exemplo essa capacidade de reestruturação e conclui: "Só através da educação de adultos podemos criar para as crianças as condições necessárias para a formação de uma nova mentalidade".

Termina sua fala sintetizando: "A abordagem comunal e de programas integrados visando à melhoria das condições gerais de saúde e de vida é a única que pode assegurar resultados duradouros e econômicos no controle de quase todas as endemias rurais".

\section{Conclusão: o que apre(e)nder com Hortênsia de Hollanda}

A educadora é extraordinário exemplo de equilíbrio e síntese entre utopia e adesão à realidade, entre rigor intelectual e grande humanidade, entre expert - mulher de cultura e educadora, sempre empenhada mas jamais subordinada a esquema ou dogma ideológico - e sujeito atravessado pela paixão permanente de conjugar teoria com ação individual e coletiva. Representa seguramente uma das contribuições mais efetivas para a saúde pública brasileira no século XX. Sua obra científica, tão intimamente unida a sua personalidade e humanidade, não é apenas um capítulo fundamental e ainda aberto da história da educação em saúde; é imprescindível ponto prático-operativo de referência para as ações educativas em saúde empreendidas por pesquisadores, trabalhadores, professores, cidadãos, grupos, movimentos, organizações e instituições que trabalham em todas as partes do mundo, envolvidos com o homem, sua saúde, sua vida.

Muito há a pesquisar nas ações e obras de Hortênsia de Hollanda: suas ideias, sua prática, sua ação e sua participação como mulher no mundo da educação em saúde.

\section{NOTAS}

*Este artigo é um dos produtos resultantes de pesquisa que contou com apoio financeiro da Fundação de Amparo a Pesquisa do Estado de Minas Gerais (Fapemig), do Conselho Nacional de Desenvolvimento Científico e Tecnológico (CNPq) e da Coordenação de Aperfeiçoamento de Pessoal de Nível Superior (Capes).

${ }^{1}$ Fundo INERu, série Administração Geral, subsérie DNERu, doc. 06.00.00/01.07.12.

${ }^{2}$ A expressão 'autoritária e normatizadora' é utilizada por Vasconcelos (1999) quando escreve sobre as transformações da educação em saúde e do relacionamento entre os serviços de saúde e a população.

\section{REFERÊNCIAS}

ALFABETIZANDO...

Alfabetizando o corpo: o pioneirismo de Hortênsia de Hollanda na educação em saúde. Direção de Virgínia Torres Schall. Belo Horizonte: Intervalo Vídeo,. 1 DVD (26 min), widescreen, color. 2001.

BIBEAU, Gilles.

The circular semantic network in Ngbandi disease nosology. Social Science and Medicine, Part B, Oxford, v.15, n.3, p.295-307. 1981.

BRASIL.

Ministério da Saúde. Secretaria de Políticas de
Saúde. Projeto Promoção da Saúde: Declaração de Alma-Ata, Carta de Ottawa, Declaração de Adelaide, Declaração de Sundsvall, Declaração de Santafé de Bogotá, Declaração de Jacarta, Rede de Megapaíses, Declaração do México. Brasília: Ministério da Saúde. 2001.

BRICEÑO-LEÓN, Roberto.

Siete tesis sobre la educación sanitária para la participación comunitária. Cadernos de Saúde Pública, Rio de Janeiro, v.12, n.1, p.7-30. 1996.

CANDEIAS, Nelly Martins Ferreira.

Conceitos de educação e de promoção em saúde: mudanças individuais e mudanças 
organizacionais. Revista de Saúde Pública, São Paulo, v.31, n.2, p.209-13. 1997.

CANDEIAS, Nelly Martins Ferreira; ABUJAMRA, Alcéa Maria David; PEREIRA, Isabel Maria Teixeira Bicudo.

Delineamento do papel profissional dos especialistas em educação em saúde: uma proposta técnica. Revista de Saúde Pública, São Paulo, v.25, n.4, p.289-98. 1991.

CANDEIAS, Nelly Martins Ferreira; RICE, Marilyn.

Padrões mínimos da prática da educação em saúde: um projeto pioneiro. Revista de Saúde Pública, São Paulo, v.23, n.4, p.347-53. 1989.

CHIAVARALLOTI NETO, Francisco; MORAES, Maria Silvia de; FERNANDES, Maria Aparecida. Avaliação dos resultados de atividades de incentivo à participação da comunidade no controle da dengue em um bairro periférico do município de São José do Rio Preto, São Paulo, e da relação entre conhecimentos e práticas desta população. Cadernos de Saúde Pública, Rio de Janeiro, v.14, supl.2, p.101-109. 1998.

COELHO, Maria Thereza Ávila Dantas;

ALMEIDA FILHO, Naomar de.

Conceitos de saúde em discursos contemporâneos de referência científica. História, Ciências, Saúde - Manguinhos, Rio de Janeiro, v.9, n.2, p.315-333. 2002.

DINIZ, Maria Cecília Pinto.

A trajetória profissional de Hortênsia de Hollanda: resgate histórico para compreensão da Educação em Saúde no Brasil. Tese (Doutorado) - Instituto René Rachou/Fiocruz, Belo Horizonte. 2007.

DINIZ, Maria Cecília Pinto; BRAGA, Rosalina Batista; SCHALL, Virgínia Torres.

As representações sociais da esquistossomose de escolares de área endêmica de Minas Gerais. Ensaio, Belo Horizonte, v.5, n.2, p.109-123. 2003.

FABREGA, Horacio.

Disease and social behavior: an interdisciplinary perspective. Cambridge: The MIT Press. 1974.

FREIRE Paulo.

Pedagogia da esperança: um reencontro com a pedagogia do oprimido. 3.ed. Rio de Janeiro: Paz e Terra. 1994.

FREIRE Paulo.

Ação cultural para liberdade e outros escritos. Rio de Janeiro: Paz e Terra. 1976.

FREIRE Paulo.

Pedagogia do oprimido. 2.ed. Rio de Janeiro: Paz e Terra. 1975.
GAZZINELLI, Maria Flávia; REIS, Dener Carlos dos; MARQUES, Rita de Cássia (Org.). Educação em saúde: teoria, método e imaginação. Belo Horizonte: Editora UFMG. 2006.

GOMES, Regina Célia Nogueira.

Formação humanista do médico: contribuições para uma reflexão na contribuição de Carl Rogers. Dissertação (Mestrado) - Faculdade de Educação, Universidade Estadual de Campinas, Campinas. 2002.

GOOD, Byron J.

Medicine, rationality and experience. New York: Cambridge University Press. 1994.

GOOD, Byron J.

The heart of what's the matter: the semantics of illness in Iram. Culture, Medicine and Psychiatry, New York, v.1, p.25-58. 1977.

HOLLANDA, Hortênsia Hurpia. Informe curricular. Rio de Janeiro. 1996.

HOLLANDA, Hortênsia Hurpia (Org.). Saúde como compreensão de vida: um programa de saúde destinado a professores e alunos de 5a a 8a série do 1o grau. Brasília: Ministério da Saúde/Convênio MEC/Premen. 1977.

\section{KLEINMAN, Arthur.}

Patients and healers in the context of culture: an exploration of the borderland between anthropology, medicine, and psychiatry. Berkeley: University of California Press.1980.

LEFÈVRE, Fernando et al.

Representações sociais sobre relações entre vasos de plantas e o vetor da dengue. Revista de Saúde Pública, São Paulo, v.38, n.3, p.405-414. 2004.

LIMA, Ana Luce Girão Soares de; PINTO, Maria Marta Saavedra.

Fontes para a história dos 50 anos do Ministério da Saúde. História, Ciências e Saúde Manguinhos, Rio de Janeiro, v.10, n.3, p.1037-1051. 2003.

LIMA, Magali Alonso; ZANCAN, Lenira P. O discurso da educação em saúde (1940-1980): uma contribuição para a história das políticas públicas de saúde no Brasil. Revista do Instituto de Ciências Humanas e Filosofia, Niterói, n.45, p. 1-40. 1991.

\section{MINKLER, Meredith.}

Building supportive ties and sense of community among the inner-city elderly: the Tenderloin Outreach Project. Health Educational Quarterly, n.12, v.4, p.303-314. 1985.

ORNELLAS, Cleusa Panissete.

Educação em saúde: prática sanitária ou 
instrumento de ação ideológica. Dissertação (Mestrado) - Escola Nacional de Saúde Pública/Fiocruz, Rio de Janeiro. 1981.

OSHIRO, Julieta Hitomi.

Educação para saúde nas instituições de saúde pública. Dissertação (Mestrado) - Pontifícia Universidade Católica, São Paulo. 1988.

PIAGET, Jean.

Inteligencia y afectividad. Buenos Aires: Aique. 2001.

PIAGET, Jean. Intelligence and affectivity: their relationship during child development. Palo Alto: Annual Reviews. Trad. de "Les relations entre

l'intelligence et l'affectivité dans le développement de l'enfant", Bulletin de Psychologie (Paris), v.7, n.3-4, p.143-150; n.6-7, p.346-361; n.9-10, p.522-535; e n.12, p.699-701 (1954). 1981.

REIS, Dener Carlos dos.

Educação em saúde: aspectos históricos e conceituais. In: Gazzineli, Maria Flávia; Reis, Dener Carlos do; Marques, Rita de Cássia (Org.). Educação em saúde: teoria, método e imaginação. Belo Horizonte: Editora UFMG. p.19-24. 2006.

ROSENBAUM, Julia et al.

Community participation in dengue prevention and control: a survey of knowledge, attitudes, and practice in Trinidad and Tobago. American Journal of Tropical Medicine and Hygiene, Baltimore, v.53, p.111-117. 1995.

SCHALL, Virgínia Torres.

Alfabetizando o corpo: o pioneirismo de Hortênsia de Hollanda na educação em saúde. Cadernos de Saúde Pública, Rio de Janeiro, v.15, n.2, p.149-159. 1999.

SCHALL, Virgínia Torres; MASSARA, Cristiano Lara; DINIZ, Maria Cecília Pinto.

Educação em saúde no controle da esquistossomose. In: Carvalho, Omar dos Santos; Coelho, Paulo Marcos Zech; Lenzi, Henrique Leonel (Org.). Schistosoma mansoni e esquistossomose: uma visão multidisciplinar. Rio de Janeiro: Ed. Fiocruz. p.1029-1079. 2008.

SILVA, Sylvia Helena Souza da.

Professor de medicina: diálogos sobre sua formação docente. Tese (Doutorado em
Educação) - Pontifícia Universidade Católica, São Paulo. 1997.

STAIANO, Kathryn.

Alternative therapeutic systems in Belize: a semiotic framework. Social Science and Medicine, Part B, Oxford, v.15, n.3, p.317-332. 1981.

VALLA, Victor Vincent.

Educação popular, saúde comunitária e apoio social numa conjuntura de globalização. Cadernos de Saúde Pública, Rio de Janeiro, v.15, p.569-579. 1999.

VASCONCELOS, Eymard Mourão. A espiritualidade no cuidado e na educação em saúde. In: Vasconcelos, Eymard Mourão (Org.). A espiritualidade no trabalho em saúde. São Paulo: Editora Hucitec. p.13-157. 2006.

VASCONCELOS, Eymard Mourão.

Educação popular: de uma prática alternativa a uma estratégia de gestão participativa das políticas de saúde. Physis: Revista Saúde Coletiva, Rio de Janeiro, v.14, n.1, p.67-83. 2004.

VASCONCELOS, Eymard Mourão.

Educação popular e a atenção à saúde da família. São Paulo: Editora Hucitec. 1999.

VIEIRA, Evaldo.

Estado e miséria social no Brasil: de Getúlio a Geisel, 1951 a 1978. São Paulo: Cortez. 1983.

VYGOTSKY, Lev Semenovich.

Teoria e método em psicologia. São Paulo:

Martins Fortes. 1996.

WALLON, Henri.

A atividade proprioplástica. In: Nadel-Brulfert J.; Werebe, M.J.G. Henri Wallon (antologia). São Paulo: Ática. 1986.

WHO.

World Health Association. Division of Mental Health. Qualitative research for health programmes. Geneva: WHO. 1994.

YOUNG, Alan.

The anthropologies of illness and sickness. Annual Review of Anthropology, Palo Alto, v.11, p.257-285. 1982.

\section{YOUNG, Alan.}

Some implications of medical beliefs and practices for social anthropology. American Anthropologist, New Orleans, v.78, n.1, p.5-24. 1976. 